\title{
Murder and Violence in Kantian Ethics
}

Acts of violence and murder have historically proved difficult to accommodate in standard accounts of the formula of universal law (FUL) version of Kant's Categorical Imperative (CI). The logical contradiction account of this principle fails to classify these actions as contrary to "narrow" and "strict" perfect duties and, while the practical contradiction interpretation classifies at least some of these actions in this way, it does so on the basis that agents proposing to use murder to further their ends could not hope to do so securely in a world in which everyone did the same. While this may be a plausible account of the moral concern at issue in acts like false promising, ${ }^{1}$ it seems to distort and misrepresent the moral problem in cases of acts of violence and killing: The wrong done in killing simply does not seem to be that it is unfair to kill someone when everyone else is refraining from doing so.

Against this background, Barbara Herman offers a distinctive and in many ways more promising model in her article "Murder and Mayhem."2 She begins by stressing that it is reasonable to require any proposed account of Kant's Categorical Imperative to be didactic in the sense that its application should reveal the wrong-making characteristic of acts that fail under this principle and by suggesting that acts of violence and killing represent an important test case in this regard. ${ }^{3}$ Developing her model with this requirement in mind, she offers a very different

1 Korsgaard suggests that in contrast to the logical contradiction account, the practical contradiction account model affords us a general understanding of the wrong involved in actions contrary to perfect duty seen in the apparent appeal of the underlying intuition that there is something unfair about acting on a maxim whose success depends on others refraining from acting in the same way:

Intuitively speaking, the test reveals unfairness, deception, and cheating. For instance, in the false promising case, the difficulty is that the man's end - getting the money - cannot be achieved by his means - making a false promise - in the world of the universalized maxim. The efficacy of the false promise as a means of securing the money depends on the fact that not everyone uses promises this way (Korsgaard, p. 92).

This way of looking at the test also shows us one sense in which violations of the universal law test imply that you are using others as a mere means. If you do something that only works because most people do not do it, their actions are making your action work. In the false promising case, other people's honesty makes your deceit effective (Korsgaard, p. 93).

2 “Murder and Mayhem: Violence and Kantian Casuistry," Monist 72 (1989), 411-43. Reprinted in Herman, 1996.

${ }^{3}$ The thought here is that if we are going to think of the CI as an authoritative guide to individual moral deliberation, it needs to do more than just seem to get the answer right in some series of canonical cases. It ought, instead, also to be informative in its application, flagging some feature(s) of maxims in virtue of which they are impermissible:

If moral judgment is to express moral understanding, and guide moral perception, there must be a way of connecting the argument of the CI procedure to a useful account of the

"wrongness" of an action. (Herman 1996, p. 116)

And: 
account of duties prohibiting acts of murder and violence and of the distinction between perfect and imperfect obligations. Herman's model has much to recommend it but I argue here that it also raises some significant questions about the status and priority of these and other duties. These concerns suggest that there is room for an alternative account and I outline one based on Kant's discussion of the perfect duty prohibiting suicide in The Metaphysics of Morals which I think has a number of advantages.

\section{I}

Herman's model of natural actions is framed by a distinctive analysis of the application of the CI. She argues that the will's capacity to be an autonomous source of ends depends on it being an independent adjudicator of reasons able to think of reasons for action as its own and capable of deciding what to do on its own terms. Maxims said to give rise to a contradiction in conception are then thought of as those which, on universalization, can be seen to be incompatible with this basic integrity (or "separateness) of wills. So, for example, a universalized maxim of deception permitting deception as a routine means in the pursuit of ends would render agents unable to reliably act for reasons of their own and is therefore incompatible with the basic integrity of rational agency and hence contradictory in this sense. In contrast, Herman argues that contradictions in the will arise when we will a universal law incompatible with the effective exercise of this agency. So, while a world in which no one helps others is compatible with the possibility of autonomous willing, we cannot consistently will a universal law like this given the natural and ineliminable dependence of the effectiveness of our agency on various essential needs being met.

Applying this version of the CI procedure's tests for universalization to the case of acts of murder and violence, Herman argues that coercive violence resembles deception in that it involves an attempt to usurp the willing of another and that in a world of universalized coercive violence agents will be similarly unable to act reliably from reasons of their own. She claims that maxims of coercive violence will therefore generate the same kind of contradiction in conception seen in the case of deception and will be regarded here as contrary to perfect duties. The same will not, however, be true of maxims involving non-coercive violence. The victim of noncoercive violence "has his will obstructed" but, while violence like this can "prevent an agent from doing what he wills," it cannot control willing and does not generate the relevant contradiction in conception on universalization (Herman 1996, p. 126). Herman therefore classifies non-coercive violence differently as contrary to imperfect duties, associating it with a contradiction in the will on the grounds that the existence and continuing functioning of our natural organism is an essential condition of our effective agency.

Reasoning in this way, Herman hopes to offer a more comprehensive analysis of the status of acts of violence and killing in Kantian ethics, and one that is didactic in the sense she indicates. Coercive and non-coercive violence are both understood to involve a failure to "assign correct value to rational agency," and this failure of proper valuing is regarded as the "content" of morally wrong action (Herman 1996, p. 124). But these different kinds of violence wrongly

Murder and mayhem are especially useful test cases for exploring the power of the CI procedure's arguments, for we take ourselves to know both that they are wrong and what it is that is the matter with them. (Herman 1996, p. 116) 
discount the conditions of willing in different ways. Like deception, coercive violence involves "an assault on the integrity of willing itself" while non-coercive violence undermines the conditions of effective agency in human agents and is classified differently. ${ }^{4}$

\section{II}

The standard problem with accounts like Herman's that associate at least some maxims of violence with contradictions in the will is that this seems to devalue central moral prohibitions on acts of murder and brutality. Imperfect duties are positive duties recommending the performance of actions like kindness and developing our talents, and are typically thought of as "wide" and less stringent in comparison to "narrow" perfect duties requiring standing and exceptionless prohibitions on certain types of actions. Herman is sensitive to this concern and argues both that there are reasons to classify duties not to kill or injure together with imperfect duties to help people in need and that, when we do so, we can still importantly distinguish between these different duties. She stresses that imperfect duties prohibiting non-coercive violence and requiring beneficence share a basic orientation around concerns with necessary conditions of human rational agency and contrasts these concerns with the more formal concern with conditions of the independence of wills seen in perfect duties prohibiting deception and coercion. At the same time, however, these different imperfect duties are oriented around concerns with human agency in importantly different ways: Duties prohibiting non-coercive violence are concerned with denials of claims of vulnerability, while duties of beneficence are concerned with the denial of claims of need. Importantly, Herman also recasts duties of beneficence as narrower and seemingly more pressing duties requiring only that we respond to the essential agency sustaining needs of others, thereby elevating the seriousness of these imperfect obligations in a way that helps reduce the impact of classifying duties prohibiting non-coercive violence in the same category as duties to be kind to others.

These considerations help ameliorate some concerns here but also raise significant questions relating to the way these different duties are understood, and the priorities attaching to them that bear on the claim that this account is appropriately didactic. While it is true, for example, that coercive violence is aimed at controlling another's actions, we might still think that, morally speaking, it is nonetheless importantly different from deception and manipulation. There is an important difference between making someone a false promise in order to borrow money and putting a gun to their head and threatening to kill or maim them or their family if they do not do as you ask. It seems to be precisely the element of violence that makes the latter distinctively troubling and this seems in danger of being lost in Herman's account. It is also not clear how we are to understand the relationship between different types of duties prohibiting coercive and noncoercive violence and, in particular, whether Herman means to retain the presumption of greater stringency usually attaching to perfect duties. Doing so would suggest, I think counterintuitively, that just in virtue of its manipulative form, coercive violence is necessarily morally worse than brute violence. On the other hand, abandoning this priority seems to render the distinction

4 "Coercion involves an attack on agency; violence, an attack on its conditions" (Herman 1996, p. 126). 
between perfect and imperfect duties casuistically inert and leaves important questions about the priority of various duties unanswered..$^{5}$

Regardless of whether Herman means to retain the priority attaching to perfect duties, I take it that the classification of duties prohibiting non-coercive violence as imperfect is certainly not meant to diminish the seriousness of these obligations. Herman connects imperfect duties with respect for basic human vulnerabilities and essential agency sustaining needs and rejects the common understanding that these are minor duties permitting exceptions in the name of selfinterest. ${ }^{6}$ Doing so, however, raises further questions about the status of different duties here. Herman's narrower understanding of beneficence helps reduce concerns about her classification of acts of non-coercive violence alongside duties to aid others, but the common focus of these obligations on essential conditions of human agency and the increased seriousness of duties of beneficence raise questions about the scope of our obligations to meet the needs of others and the relative priority of these different concerns. Ought we, for example, to prioritize attempts to feed the starving over efforts at reducing violence at home or abroad? In addition, Herman's account of the contradiction in conception evident in maxims of non-beneficence leaves the moral status of mundane acts of kindness and other less serious duties uncertain. Herman stresses here that obligations like this are not "without moral structure or content," but argues that "they have a different moral structure, one that parallels the difference between interests and true needs" (Herman 1996, p. 71). On her account, however, it is only neglect of essential agency sustaining needs that gives rise to a contradiction in the will. As such, it is not clear where this "moral structure and content" is to come from or how it can be reconciled with the status of the CI as the sole fundamental principle of all moral obligation. ${ }^{7}$

5 Kantians are often willing to "bite the bullet" here apparently retaining the priority of perfect duties and singling out deception and coercion for uniquely serious condemnation. Korsgaard, for example, suggests that in Kantian ethics deception and manipulation are "the most fundamental forms of wrongdoing to others - the root of all evil" (Korsgaard, p. 140).

It is not, however, clear what Herman's view of this issue is. She stresses that the wrong done in murder and violence lies in the failure to assign proper value to rational agency in one's willing and not in the consequences for the victim and suggests that "coercion involves a more direct attack on agency than does any act of (mere) violence" (Herman 1996, p. 126). Elsewhere she again seems to emphasize the priority of concerns with deception and coercion in suggesting that while it may be possible to justify deception in some circumstances, "the value of agential integrity never permits exceptions (violation) for the sustenance of life or the provision of true needs" (Herman 1996, p. 156). She does not, however, explicitly address this issue of priority.

I cannot argue for this here but I think it is a mistake to distinguish coercion and deception in this way. It seems to me implausible to maintain that we should think of even relatively minor acts of deception as morally worse than acts of murder and brutality just in virtue of their form and I take it as an advantage of the account I propose here that it does not do so.

${ }^{6}$ See, for example, her discussion of the latitude associated with imperfect duties in Herman 2007, Ch. 9, p. 213-215.

${ }^{7}$ I discuss Herman's analysis of beneficence and the scope of this duty further in (REF) 
I do not mean to suggest that concerns like these represent insurmountable difficulties for Herman's account, but questions like these suggest that the claim that this is a didactic account significantly improving on the alternatives requires more discussion and that there may be room for improvement. With this in mind, I want to propose an alternative account suggested by Kant's treatment of the duty prohibiting suicide in The Metaphysics of Morals: one that preserves the priority attaching to perfect duties and offers us, I think, a unified and more plausible account of the wrong involved in natural actions.

Herman is skeptical about the prospects of using Kant's discussion of suicide in the Groundwork as a model for the handling of natural actions in Kantian ethics, suggesting that it is not clear what the argument here is or how it could be generalized to offer an account of acts of murder and violence directed at others. The account Kant offers in his later Metaphysics of Morals is, however, much clearer and more direct and is immediately didactic in the sense Herman stresses is required. Kant classifies the duty prohibiting suicide in this later work as one of a series of perfect duties of virtue owed to ourselves concerned with "inner freedom" (MS 6:420) and thus with "the capacity for self-constraint not by means of other inclinations but by pure practical reason" (MS 6:396). As imperfectly rational beings always subject to competing incentives, human beings realize their rational natures only in this kind of self-conscious choice of rational self-government, and hence only through the development and exercise of this kind of freedom. The perfect duties that Kant discusses here require respect for the basic conditions of this kind of freedom and therefore for conditions of the possibility of rational agency in sensibly affected human beings. So, for example, drunkenness is regarded as incompatible with the required concerns with conditions of our moral health and hence as contrary to perfect duties because it robs us of the capacity to use our powers in the service of rational self-constraint. Perfect duties oriented in this way are then associated with concerns with our moral health and contrasted with imperfect duties oriented around considerations of moral prosperity requiring respect for the conditions necessary for the effective exercise of rational agency. Thus, while our capacity to constrain ourselves on the basis of reason rather than self-love does not depend on our perfecting our talents, doing so nonetheless contributes positively to the effective realization of this kind of inner freedom in choice and life and is therefore associated, instead, with imperfect duties concerned with our moral prosperity.

On this account, killing or mutilating oneself is regarded as incompatible with the required concerns with our moral health and hence as contrary to perfect duties because doing so deprives one of "certain integral organic parts" and therefore the "capacity for the natural (and so indirectly for the moral) use of one's powers" (MS, 6:421). Thus understood, the wrong done in suicide consists in the failure to respect the integrity and proper functioning of our bodies that is a necessary conditions of our rational agency and the relevant prohibition will extend not just to acts of killing and self-mutilation, but also to concerns with our psychological condition prohibiting us, for example, from engaging in behaviors likely to cause us to fall victim to debilitating depression to the detriment of our capacity to reason properly about how to act.

I propose that we use this account of suicide as a model for a more general understanding of norms of non-violence in Kantian ethics. There is no reason why Kant would think of the moral wrong in self-murder as categorically different from other-murder - if killing a rational agent in 
one's own person in order to reduce discomfort is wrong, it seems reasonable to think that killing another person for similar reasons will be wrong also, and be wrong for the same general reason(s). ${ }^{8}$ This is not to claim that duties like these will necessarily have the same scope or will allow the same exceptions or qualifications. I mean to suggest only that in cases where the CI prohibits the same kind of actions (or similar maxims) involving ourselves or others, we ought to expect these duties to share a common concern. It therefore seems reasonable to suggest that the wrongs involved will be similar in character and hence that we can use this account of the wrong in suicide to inform our understanding of acts of killing and violence directed at others. Thus understood, acts of killing and violence directed at others will be regarded as wrong on the grounds that they involve the same kind of failure to respect the integrity and proper functioning of the physical organism in which human rational agency is instantiated and hence as similarly contrary to perfect duties requiring respect for the basic conditions of our own and others' rational agency.

This is a straightforward and seemingly more plausible account of the wrong done in killing and violence. The general concerns required here with conditions of agency will still encompass the kind of prohibitions on deception and coercive violence that Herman stresses. We realize our inner freedom (and hence our rational nature) only in conscious self-constraint expressing our own internal ordering of values and priorities and a reflectively endorsed and ongoing commitment to prioritizing the requirements of reason over our other interests. As such, the respect required of us will extend to similarly broad and robust concerns with agents independence from others' wills. On this account, however, the required concerns with agency encompass broader concerns with the integrity and proper functioning of our physical organism and psychological condition. ${ }^{9}$ This allows us to classify duties prohibiting murder and non-

${ }^{8}$ Responding to problems arising from the alleged peculiarity of self-regarding duties, Andrews Reath emphasizes the same underlying commonality in obligations arguing that moral requirements governing our conduct towards other persons apply equally to ourselves as persons:

I see no special problem in understanding how one can have duties to oneself, especially in the context of a Kantian theory in which respecting humanity as an end in itself plays a defining role. For there to be duties to oneself, we must have non-prudentially based reasons for adopting certain attitudes towards (certain aspects of) ourselves - for example, for valuing certain of our powers and capacities, interests, our moral standing, and so on. The absolute value of humanity provides a perfectly general basis for respecting such capacities and interests in any human being. That we as agents are in a special position either to support or, on the other hand, to neglect or undermine the relevant capacities and interest in ourselves, and that we can and do act in ways that evidence failure to accord proper value to these capacities and interests, give us occasion to apply to ourselves the general reasons stemming from the absolute value of humanity (Reath, p. 349).

${ }^{9}$ For a more comprehensive discussion of the form that respect for others' moral agency will take here see [REF, 2014, 2009, 2007]. I argue in these papers that concerns with others' moral agency will require consideration of a broad range of material and social circumstances and psychological factors bearing on the capacity of others to order and control their lives in general and to realize their moral natures for themselves. These will include both concerns with adverse conditions incompatible with the development and realization of our moral agency and with those positively conducive to it. So, for example, the required concerns will commit us to basic norms of non-interference and to the kind of social world respectful of others' external freedom that Kant describes in the Doctrine of Right. More positively, however, these concerns will also include a broader range of norms enjoining an active 
coercive violence alongside concerns with deception and coercion as contrary to perfect duties requiring respect for the basic conditions of rational agency in human beings.

On this view, then, coercive and non-coercive violence are both regarded as contrary to perfect duties and can be thought of as sharing a serious form of wrong, in contrast to imperfect duties concerned with moral prosperity and thus with the perfection of our own and others' moral agency. This account therefore allows us to classify acts of violence together and to importantly distinguish these and other perfect duties in a way that suggests they will retain the priority typically associated with this classification. At the same time, the common and serious moral concern with the integrity and proper functioning of our bodies and minds preserves the connection between coercive and non-coercive violence, distinguishing coercion from deception and allowing us to properly acknowledge the distinctive wrong in violence. Lastly, the classification of imperfect duties as duties oriented around concerns with conditions of moral prosperity avoids the problematic marginalization of smaller acts of kindness and support alluded to above that seems to result from Herman's re-classification of imperfect duties as duties concerned only with essential agency sustaining needs.

There is obviously a great deal more that needs to be said and, unfortunately, I can only gesture at the development of this account here. In closing, however, I should stress that I mean this proposal as a friendly amendment to Herman's view and, in particular, that I do not think of it as adding to the metaphysical burden associated with her account. ${ }^{10}$ Like most commentators, Herman is sensitive to background concerns about the conception of rationality and agency her account involves. She is, however, already committed to the idea that reason requires respect for the conditions of effective rational agency in distinguishing between formal conditions of the integrity of wills and further conditions of agency particular to human willing, and in using this distinction to mark the difference between perfect and imperfect duties. I propose simply that we move the boundary here. It seems to me that instantiation - and hence the integrity and proper functioning our bodies - is just as much an essential condition of willing and agency as independence from the wills of others, and that it is therefore artificial to distinguish between formal conditions of agency and material (or "human") conditions of agency in the manner Herman suggests. I propose, therefore, that we think of concerns with the integrity of willing more broadly as encompassing concerns with material conditions of agency equally essential to rational self-determination in human beings. Doing so affords us a more plausibly didactic account of natural actions that allows us to think of these as serious moral wrongs on a par with deception and coercive violence, and has, I think, the potential to offer us more subtle and interesting account of moral life.

sensitivity to the efforts of others to organize and control their own lives and that we seek to ensure a public culture respectful of different choices and supportive of others' efforts to realize their moral natures for themselves.

${ }^{10} \mathrm{I}$ discuss the implications of this account for our understanding of the contradictions in conception and in the will associated with the CI further in [REF 2005] 


\section{Bibliography}

Engstrom, Stephen. 2002. “The Inner Freedom of Virtue," in Kant's Metaphysics of Morals: Interpretive Essays, Mark Timmons (Ed.). Oxford: Oxford University Press.

Herman, Barbara. 1996. The Practice of Moral Judgment. Cambridge, MA: Harvard University Press.

--- 2007. Moral Literacy. Cambridge, MA: Harvard University Press.

Kant, Immanuel. 1974. Anthropology from a Pragmatic Point of View, trans. M. J. Gregor. The Hague: Martinus Nijhoff.

--- 1991. The Metaphysics of Morals, trans. Mary J. Gregor. Cambridge, UK: Cambridge University Press.

--- 1991. Groundwork of the Metaphysics of Morals, trans. Mary J. Gregor. Cambridge, UK: Cambridge University Press.

Korsgaard, Christine M. 1996. Creating the Kingdom of Ends, Cambridge UK: Cambridge University Press

O'Neill, Onora. 1990. Constructions of Reason. Cambridge UK: Cambridge University Press.

Potter, Nelson. 2002. "Duties to Oneself in Kant's Ethics,"Kant's Metaphysics of Morals:

Interpretive Essays, Mark Timmons (ed.). Oxford: Oxford University Press.

Reath, Andrews. 2002. "Self-Legislation and Duties to Oneself," in Kant's Metaphysics of Morals: Interpretive Essays, Mark Timmons (Ed.). Oxford: Oxford University Press.

Wilson, Donald, 2014. "Norms of Truthfulness and Non-Deception in Kantian Ethics," Rethinking Kant, 2014.

--- “Moral Reflection and Desire Development: Herman on Alienation,” Canadian Journal of Philosophy, June 2009

--- "Middle Theory, Inner Freedom, \& Moral Health," History of Philosophy Quarterly, October 2007

---- “Moral Health, Moral Prosperity, and Universalization in Kant’s Ethics,” Teorema, 2005 